\title{
Cross-sectional examination of metabolites and metabolic phenotypes in uremia
}

\author{
Sahir Kalim ${ }^{1 *}$, Clary B. Clish², Joseph J. Deferio ${ }^{1}$, Guillermo Ortiz ${ }^{1}$, Alexander S. Moffet ${ }^{1}$, Robert E. Gerszten ${ }^{2,3,4}$, \\ Ravi Thadhani ${ }^{1}$ and Eugene P. Rhee ${ }^{1,2}$
}

\begin{abstract}
Background: Although metabolomic approaches have begun to document numerous changes that arise in end stage renal disease (ESRD), how these alterations relate to established metabolic phenotypes in uremia is unknown.

Methods: In 200 incident hemodialysis patients we used partial least squares discriminant analysis to identify which among 166 metabolites could best discriminate individuals with or without diabetes, and across tertiles of body mass index, serum albumin, total cholesterol, and systolic blood pressure.

Results: Our data do not recapitulate metabolomic signatures of diabetes and obesity identified among individuals with normal renal function (e.g. elevations in branched chain and aromatic amino acids) and highlight several potential markers of diabetes status specific to ESRD, including xanthosine-5-phosphate and vanillylmandelic acid. Further, our data identify significant associations between elevated tryptophan and long-chain acylcarnitine levels and both decreased total cholesterol and systolic blood pressure in ESRD. Higher tryptophan levels were also associated with higher serum albumin levels, but this may reflect tryptophan's significant albumin binding. Finally, an examination of the uremic retention solutes captured by our platform in relation to 24 clinical phenotypes provides a framework for investigating mechanisms of uremic toxicity.
\end{abstract}

Conclusions: In sum, these studies leveraging metabolomic and metabolic phenotype data acquired in a well-characterized ESRD cohort demonstrate striking differences from metabolomics studies in the general population, and may provide clues to novel functional pathways in the ESRD population.

Keywords: Dialysis, Metabolism, Metabolomics, Uremic toxins

\section{Background}

End stage renal disease (ESRD) is characterized by various metabolic disturbances linked to adverse outcomes, but the nature of these associations is poorly understood or even counterintuitive [1]. For example, low serum albumin has consistently been linked to cardiovascular mortality in dialysis [2,3], yet the association is not simply a result of inadequate nutrition, as intradialytic parenteral nutrition does not always improve survival in malnourished ESRD patients [4], and alternative pathways including inflammation are known to contribute [5]. Dyslipidemia is also common in ESRD, including atherogenic increases in carbamylated and oxidized-LDL cholesterol. Clinical

\footnotetext{
*Correspondence: skalim@mgh.harvard.edu

${ }^{1}$ Division of Nephrology, Massachusetts General Hospital (MGH), 165

Cambridge Street, Suite 302, Boston, MA 02114, USA

Full list of author information is available at the end of the article
}

trials, however, have failed to demonstrate a survival benefit with statin therapy in ESRD, despite substantial reductions in LDL cholesterol [6, 7]. Indeed, several studies have identified an inverse association between cholesterol levels and uremic cardiovascular risk [8,9]. Similar paradoxical associations, sometimes described as examples of 'reverse epidemiology' in ESRD, have been noted with body mass index (BMI) and blood pressure $[8,10-12]$ and survival on hemodialysis.

Metabolomic approaches enable high resolution interrogation of metabolic phenotypes. For example, studies have begun to highlight specific metabolites associated with obesity and diabetes risk in the general population, particularly branched-chain and aromatic amino acids, but also short chain acylcarnitines, the glutamate/glutamine ratio, and bile acids [13-23]. Ultimately, these findings may lead to a more refined understanding of 
underlying disease mechanisms. Whether these and other associations identified in the burgeoning metabolomics literature extend to the ESRD population is unknown. While initial applications of metabolomics to nephrology research have generated a broad view of uremia [24] and the immediate effects of the hemodialysis procedure $[25,26]$, no studies have explicitly examined the crosssectional relationship between uremic metabolite alterations and metabolic or other clinical phenotypes captured in a given ESRD study population.

We recently performed liquid chromatography-mass spectrometry (LC-MS) based metabolite profiling on plasma obtained from incident hemodialysis subjects in the Accelerated Mortality on Renal Replacement (ArMORR) cohort, and highlighted baseline levels of long-chain acylcarnitines as markers of future cardiovascular death in a longitudinal study [27]. Using this data set, we now leverage the rich clinical phenotyping available in ArMORR to examine cross-sectional associations between plasma metabolite levels and select metabolic phenotypes. Specifically, we sought to identify associations between metabolites and metabolic phenotype data in this well-characterized ESRD cohort, hypothesizing that these findings would differ from metabolomic associations derived from the general population. The aim of such work is to gain new insights into the functional metabolic pathways that underlie the poorly understood associations between clinical outcomes in ESRD and variables such as BMI, albumin, cholesterol, and blood pressure. Further, we examined the correlation between the subset of metabolites measured by our platform that are known uremic retention solutes and numerous clinical variables captured in ArMORR. Taken together, these results provide a new perspective on the metabolic disturbances that accompany and arise in ESRD.

\section{Methods}

\section{Study population}

The Accelerated Mortality on Renal Replacement (ArMORR) study is a prospective cohort study of 10,044 incident hemodialysis patients in any of 1,056 U.S. centers operated by Fresenius Medical Care North America between June 2004 and August 2005. Full details have been previously published [27-31]. All subjects underwent 1 year of follow-up except for those who died (15.2\%), voluntarily discontinued dialysis (5\%), underwent kidney transplantation (3\%), recovered renal function (4\%), or transferred to a dialysis unit outside the Fresenius system (12\%). Clinical data were prospectively collected by physicians at the point-of-care and included demographics, coexisting conditions, and routine laboratory studies. Plasma samples drawn at the beginning of a dialysis session within 14 days of initiation of outpatient hemodialysis, and that would otherwise have been discarded after routine clinical testing, were saved and stored in liquid nitrogen. We previously evaluated the associations between metabolite profile and mortality in the ArMORR cohort in a study of 100 randomly selected patients who died within the first year of dialysis from a cardiovascular cause, and 100 patients who were alive 1 year after starting dialysis, frequency matched for age, sex, and race [27]. We included this entire group of individuals in the current study. This study was approved by the Massachusetts General Hospital IRB, which waived the need for informed consent because all personal identifiers were removed from the blood samples and clinical data before transfer to the investigators.

\section{Metabolite profiling}

We applied two distinct LC-MS based methods to distinct plasma aliquots for each study subject. Amino acids, amino acid derivatives, urea cycle intermediates, nucleotides and other positively charged polar metabolites were profiled as previously described [14]. Briefly, $10 \mu \mathrm{L}$ of plasma were extracted with $90 \mu \mathrm{L}$ of 74.9:24.9:0.2 vol/vol/ $\mathrm{vol}$ acetonitrile/methanol/formic acid containing valine-d8 (Sigma-Aldrich; St Louis, MO). After centrifugation, supernatants underwent hydrophobic interaction chromatography using a $150 \times 2.1 \mathrm{~mm}$ Atlantis hydrophobic interaction chromatography column (Waters, Milford, MA), and MS data were acquired on a 4000 QTRAP triple quadrupole mass spectrometer (AB SCIEX, Foster City, CA) using ESI and MRM in the positive ion mode. Organic acids, sugars, bile acids, and other negatively charged polar metabolites were profiled as previously described [32]. Briefly, $30 \mu \mathrm{L}$ of plasma were extracted with the addition of four volumes of 80:20 vol/vol methanol/ water containing isotope-labeled inosine-15 N4, supernatants underwent chromatography on a $150 \times 2.0 \mathrm{~mm}$ Luna NH2 column (Phenomenex; Torrance, CA), and MS data were acquired using a 5500 QTRAP triple quadrupole mass spectrometer (AB SCIEX; Foster City, CA) using ESI and MRM in the negative ion mode.

\section{Statistical analyses}

We first examined the association between plasma metabolites and pre-selected metabolic phenotypes: diabetes status, BMI, serum albumin, total cholesterol, and systolic blood pressure (SBP). We focused on these phenotypes because of their strong links to metabolism and their established, but incompletely understood, associations with ESRD mortality [33-39]. To investigate differences in metabolite profiles across these phenotypes, continuous outcomes measures (BMI, albumin, total cholesterol, and SBP) were divided into tertiles. Diabetes status was classified as "yes" or "no".

Because of the number of metabolites measured by our LC-MS platform (166 total, Additional file 1: Table S1), many with significant inter-correlations, we performed 
partial least squares discriminant analysis (PLS-DA) to visualize the linear components that discriminate individuals across the categories (tertiles or class) of metabolic phenotypes. PLS-DA was performed on log transformed and auto-scaled (mean-centered and divided by the standard deviation of each metabolite) data using MetaboAnalyst 2.0 [40, 41]. This program performs PLS regression using the plsr function provided by the pls package in $\mathrm{R}$, and classification and cross validation using the corresponding wrapper function offered by the caret package. Variable Importance in Projection (VIP) scores generated by this program estimate the importance of each variable in the projection used within the PLS model. A variable with a VIP score greater than 1 can be considered important in a given model. The metabolites with the highest VIP scores were further analyzed by comparing their levels across classes using Mann-U-Whitney and Kruskal-Wallis tests as appropriate.

Finally, heatmaps were created to represent Pearson correlation (r) and $P$-value matrices between available clinical variables in the cohort and the subset of metabolites measured by our platform that have previously been described as uremic retention solutes (http://www.uremic-toxins.org) [27, 42-45].

To account for multiple testing, we used a Bonferroni corrected significance threshold of $P<0.0003(0.05 / 166)$ for comparisons of individual metabolites across phenotype class. For the correlation matrices, we used an adjusted significance threshold of $P<0.00007$ (0.05/[29 metabolites* 24 clinical variables]). A sensitivity analysis was performed to gauge the influence of case-control status (i.e. whether or not a given individual died of a cardiovascular cause within one year of starting dialysis) on the associations described herein. Stratified analysis by case status did not alter the statistical significance of the models described. Therefore, we did not stratify models by mortality status and analyzed the entire group of 200 individuals together as a cohort. All analyses were performed using SAS software version 9.1.3 (SAS Institute) and MetaboAnalyst 2.0 software (www.metaboanalyst.ca).

\section{Results and discussion}

\section{Cohort characteristics}

As shown in Table 1, the mean age of the study population was 69.5 years and $69 \%$ of subjects were white. There was an equal representation of males and females and nearly half of the individuals had a history of diabetes or had diabetes listed as their cause of ESRD (49\%). The mean BMI was $26.5 \mathrm{~kg} / \mathrm{m}^{2}\left(\mathrm{SD} \pm 7.6 \mathrm{~kg} / \mathrm{m}^{2}\right)$ and the mean $\mathrm{SBP}$ was $144 \mathrm{mmHg}( \pm 27 \mathrm{mmHg})$. A minority of individuals reported a lipid disorder (12\%) and the median total cholesterol level was $162 \mathrm{mg} / \mathrm{dL}$ (quartile1-quartile3, $127-188 \mathrm{mg} / \mathrm{dL})$. The median serum albumin level was $3.6 \mathrm{~g} / \mathrm{dl}(3.2-3.8 \mathrm{~g} / \mathrm{dL})$.
Table 1 Baseline characteristics of the study sample

\begin{tabular}{|c|c|}
\hline Variable & Total $n=200$ \\
\hline Age, years & $69.5 \pm 13.6$ \\
\hline Male & $53 \%(106)$ \\
\hline \multicolumn{2}{|l|}{ Race } \\
\hline White & $69 \%(138)$ \\
\hline Black & $24 \%(48)$ \\
\hline Other & $7 \%(14)$ \\
\hline \multicolumn{2}{|l|}{ Coexisting conditions } \\
\hline Coronary artery disease & $18 \%(36)$ \\
\hline Lipid disorders & $12 \%(23)$ \\
\hline Congestive heart failure & $18 \%(35)$ \\
\hline \multicolumn{2}{|l|}{ Cause of end-stage renal disease } \\
\hline Diabetes $^{a}$ & $49 \%(97)$ \\
\hline Hypertensive renal disease & $38 \%(75)$ \\
\hline Glomerulonephropathy & $4 \%(7)$ \\
\hline \multicolumn{2}{|l|}{ Vascular access } \\
\hline Fistula & $24 \%(47)$ \\
\hline Graft & $13 \%(25)$ \\
\hline Catheter & $59 \%(118)$ \\
\hline Body Mass Index $\left(\mathrm{kg} / \mathrm{m}^{2}\right)$ & $26.5 \pm 7.6$ \\
\hline Systolic blood pressure $(\mathrm{mmHg})$ & $144.4 \pm 27.3$ \\
\hline Diastolic blood pressure (mmHg) & $72.5 \pm 18.6$ \\
\hline Urea reduction ratio & $68.6 \pm 10.3$ \\
\hline \multicolumn{2}{|l|}{ Laboratory data } \\
\hline N-terminal pro-BNP (ng/L) & $8029(3,757-21,404)$ \\
\hline Troponin T ( $\mu \mathrm{g} / \mathrm{L})$ & $0.14(0.04-0.13)$ \\
\hline Total cholesterol (mg/dL) & $162(127-188)$ \\
\hline $\mathrm{LDL}(\mathrm{mg} / \mathrm{dL})$ & $83(63-103)$ \\
\hline $\mathrm{HDL}(\mathrm{mg} / \mathrm{dL})$ & $41(32-47)$ \\
\hline Triglycerides (mg/dL) & $157(93-199)$ \\
\hline Creatinine $(\mathrm{mg} / \mathrm{dL})$ & $5.7(4.0-7.0)$ \\
\hline White blood cell $\left(10^{9} / \mathrm{L}\right)$ & $8.3(6.2-9.8)$ \\
\hline Hemoglobin (g/dL) & $10.4(9.5-11.2)$ \\
\hline Albumin (g/dL) & $3.5(3.2-3.8)$ \\
\hline Ferritin (ng/mL) & $285.7(81.5-346.0)$ \\
\hline Transferrin saturation (\%) & $20.2(13.0-24.0)$ \\
\hline Phosphorus (mg/dL) & $4.5(3.4-5.4)$ \\
\hline Parathyroid hormone $(\mathrm{pg} / \mathrm{mL})$ & $268.6(124.0-235.0)$ \\
\hline
\end{tabular}

Categorical data are percentages (counts). Counts may not equal total $\mathrm{n}$ due to missing data. Clinical measures are means \pm SD. Laboratory values are median (quartile 1 - quartile 3 )

BNP, brain natriuretic peptide

ancludes all patients with diabetes

\section{Examination of metabolite profiles and select metabolic phenotypes}

The PLS-DA approach allowed us to visualize and extract the metabolites that best separated individuals (Figs. 1,2,3,4 

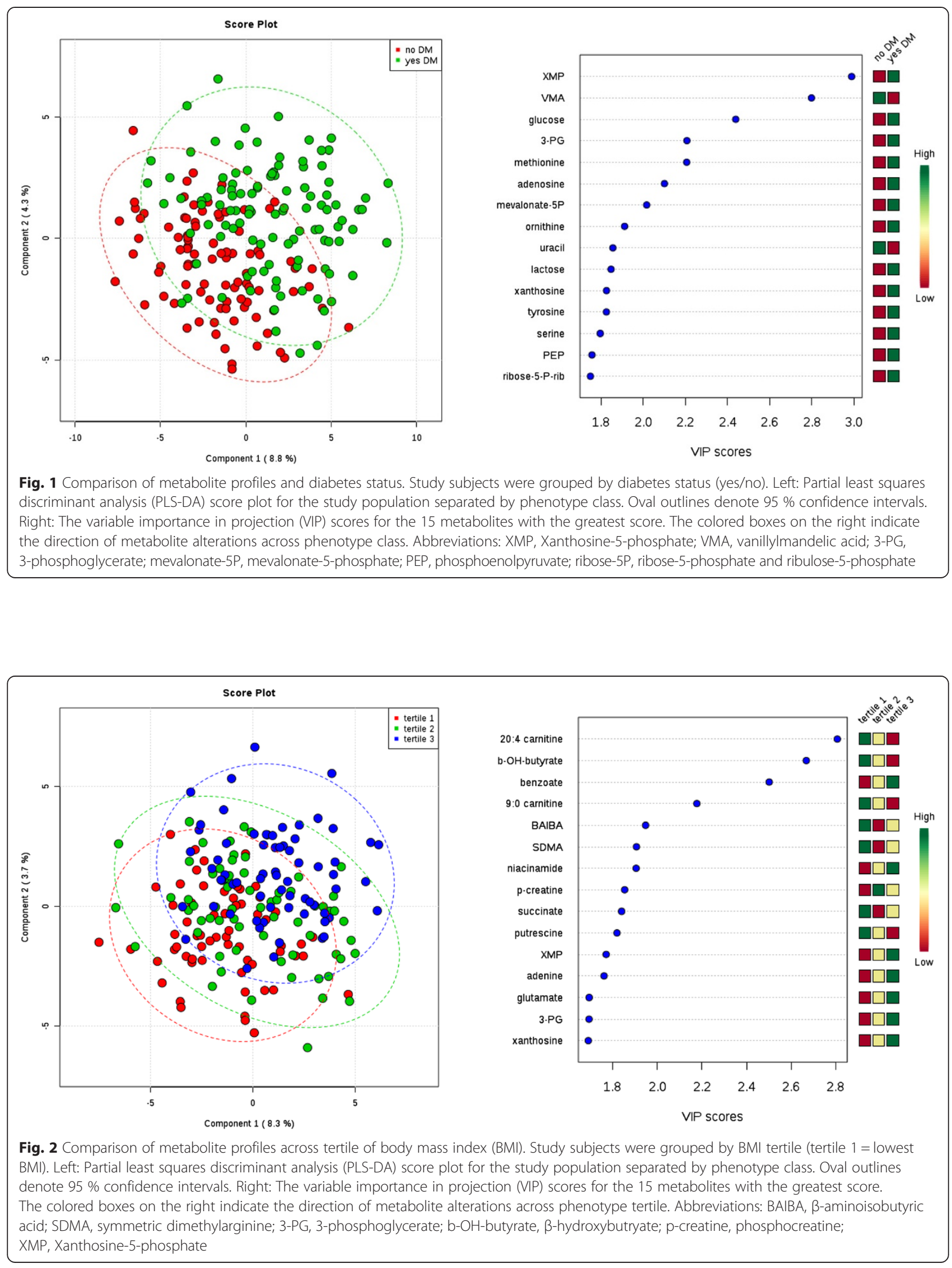

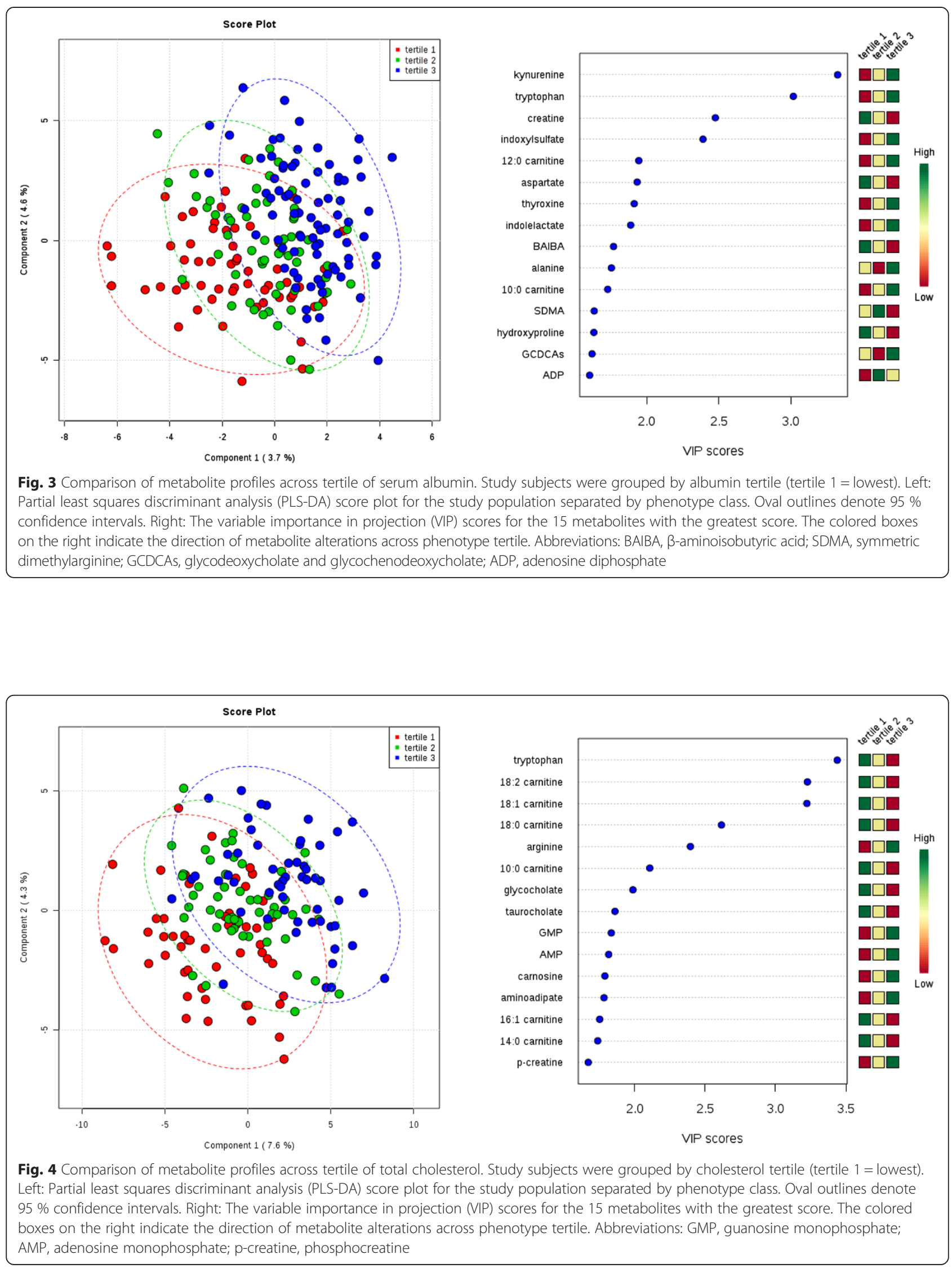
and 5; left panels) across phenotype tertile or class (Table 2). Because four of the clinical phenotypes we studied (BMI, serum albumin, total cholesterol, and SBP) are continuous measures, we recognize that tertile cut-offs do not demarcate distinct physiologic or pathophysiologic processes. Thus, plot overlap across tertiles was expected. Variable importance in projection (VIP) provided a score for each metabolite, ranking the metabolites according to their predictive power in the PLS model; the fifteen metabolites with the highest VIP scores for each plot are shown in Figs. 1, 2, 3, 4 and 5 (right panels), and the levels of these metabolites across tertiles (or class) of the phenotypes with corresponding test statistics are shown in Tables 3-7.Values are median peak area for the metabolites (quartile 1, quartile 3)*P-value significant at the Bonferroni adjusted level of $3.0 \times 10-4$

For individuals with or without diabetes, glucose was one of the strongest discriminating metabolites, with higher levels among the individuals with diabetes (Fig. 1). Xanthosine-5-phosphate (XMP) and vanillylmandelic acid (VMA), however, had even higher VIP scores than glucose, with XMP levels higher and VMA levels lower among the individuals with diabetes $\left(P=5.0 \times 10^{-7}\right.$ and $1.5 \times 10^{-6}$ for $\mathrm{XMP}$ and VMA, respectively). Other significant differences included higher levels of 3-phosphoglyceric acid $(P=4.9 \times$ $\left.10^{-5}\right)$, methionine $\left(P=4.5 \times 10^{-5}\right)$, mevalonate-5-phosphate $\left(P=2.8 \times 10^{-4}\right)$, and ornithine $\left(P=3.2 \times 10^{-4}\right)$ among individuals with diabetes. Tyrosine, an aromatic amino acid, had a nominal association with diabetes status $\left(P=1.0 \times 10^{-3}\right)$. There were no significant associations between tyrosine levels, or any aromatic or branchedchain amino acid levels, with BMI (Table 4). In fact, none of these metabolites had even a nominal association with BMI in univariate comparisons (data not shown). Overall, the ability of metabolite profiles to discriminate individuals across tertiles of BMI was poor (Fig. 2). Among the top metabolites by VIP score, only 20:4 carnitine (arachidonyl carnitine), $\beta$-hydroxybutyrate, and benzoate had nominal $P$-values in univariate analysis (Table 4 ).Values are median peak area for the metabolites (quartile 1, quartile 3) P-value significant at the Bonferroni adjusted level of $3.0 \times 10-4$ Values are median peak area for the metabolites (quartile 1, quartile 3)*P-value significant at the Bonferroni adjusted level of $3.0 \times 10-4$

Thus, our data from an ESRD population do not recapitulate observations derived in the general population linking diabetes and obesity with elevations in branched chain and aromatic amino acids (except for the nominal association with tyrosine noted above), short chain acylcarnitines, the glutamate/glutamine ratio, or bile acids [2]. One potential explanation is that kidney function (and dysfunction) has a direct effect on select metabolites. The interaction between kidney function and amino acid metabolism, in particular, has been closely examined. For example, the kidney is known to make a substantial contribution to whole body tyrosine appearance via intra-

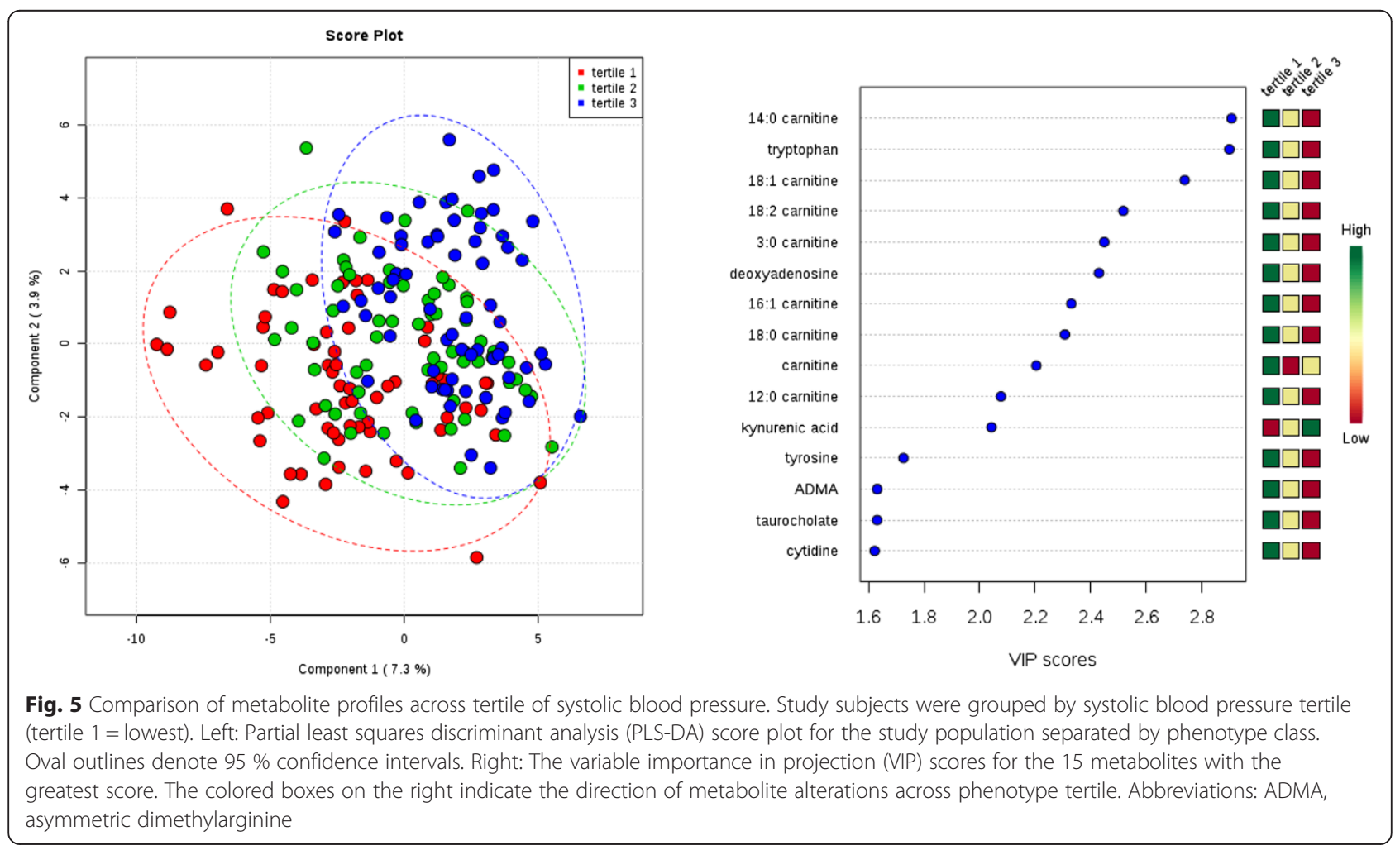


Table 2 Primary metabolic phenotypes by tertiles

\begin{tabular}{lll}
\hline & Tertile & Measure \\
\hline Body mass index $\left(\mathrm{kg} / \mathrm{m}^{2)}\right.$ & 1 & $20.2 \pm 3.9$ \\
& 2 & $25.6 \pm 1.3$ \\
Albumin $(\mathrm{g} / \mathrm{dl})$ & 3 & $34.2 \pm 7.6$ \\
& 1 & $3.1(2.8,3.2)$ \\
& 2 & $3.6(3.4,3.7)$ \\
Cholesterol $(\mathrm{mg} / \mathrm{dl})$ & 3 & $4.0(3.8,4.2)$ \\
& 1 & $116.0(106.0-126.0)$ \\
Systolic blood pressure $(\mathrm{mmHg})$ & 1 & $154.0(146.0-163.0)$ \\
& 3 & $209.5(188.0-236.0)$ \\
& 2 & $116.1 \pm 10.0$ \\
& 3 & $142.2 \pm 7.0$ \\
\hline
\end{tabular}

Clinical measures are mean \pm SD and laboratory values are median (quartile 1 to quartile 3 )

Total $n=200$

organ phenylalanine hydroxylation [46]. Further, the metabolic acidosis that results from renal failure leads to increased leucine oxidation [47], and indeed, generalized muscle catabolism. The significant associations we did identify with diabetes status in ESRD, e.g. XMP (a purine breakdown product) and VMA (a catecholamine metabolite), have not been reported in the general population. To what extent these alterations reflect distinct pathophysiologic processes in uremia warrant further investigation.

For individuals in different tertiles of serum albumin, PLS-DA demonstrated moderate separation across groups (Fig. 3). Tryptophan and its downstream metabolite kynurenine were significantly higher in individuals with higher serum albumin levels $\left(P=1.8 \times 10^{-4}\right.$ and $2.5 \times 10^{-4}$, respectively). Two additional tryptophan metabolites, indoxyl sulfate and indole lactate, had a trend for higher levels among individuals with higher serum albumin levels. Given recent observations that ascribe a functional role for tryptophan metabolism, specifically through indoleamine-2, 3-dioxygenase (IDO), in modulating the immune system and vascular tone $[48,49]$, it is an appealing link between metabolism, nutritional status, inflammation, and cardiovascular risk in ESRD. However, these data should be interpreted with caution. Because tryptophan and its catabolites are hydrophobic, their positive correlation with albumin may reflect their significant protein-binding [50] - our LC-MS method measures total, not free, plasma metabolite levels. A similar mechanism may underlie the trend for association between thyroxine and albumin levels. By contrast, creatine, the metabolite with the third highest VIP score, had a trend for higher levels among individuals with lower serum albumin levels. In a study that examined spent media from cultured muscle cells treated with mitochondrial respiratory chain inhibitors, as well as plasma obtained from individuals with respiratory chain diseases, creatine levels were reproducibly elevated [51]. In cell culture, extracellular creatine was inversely correlated with the intracellular phosphocreatine/creatine ratio, suggesting that elevated plasma creatine may signal a low energetic state in tissues using the creatine phosphate shuttle. Interestingly, elevated plasma creatine and decreased plasma phosphocreatine levels both have a nominal association with

Table $\mathbf{3}$ Cross sectional analysis of diabetes status and select metabolites

\begin{tabular}{|c|c|c|c|}
\hline & no DM & DM & $P$ \\
\hline$\overline{X M P}$ & $13585(8$ 386, 29 579) & 62101 (14 261, 158 938) & $5.0 \mathrm{E}-7^{*}$ \\
\hline VMA & $173153(107$ 165, 279 690) & $104186(67902,164683)$ & $1.5 \mathrm{E}-6^{*}$ \\
\hline Glucose & $2935(1046,5$ 294) & $6245(2777,9$ 807) & $3.1 \mathrm{E}-6^{*}$ \\
\hline 3-PG & $2475150(1882036,333$ 2264) & $3767372(2250378,5598$ 373) & $4.9 \mathrm{E}-5^{*}$ \\
\hline Methionine & $195026(152633,239$ 841) & $243230(195219,283$ 910) & $4.5 \mathrm{E}-5^{*}$ \\
\hline Adenosine & $1942(1463,3$ 457) & $3078(1706,5$ 137) & $8.6 \mathrm{E}-4$ \\
\hline mevalonate-5P & $192139(136927,291930)$ & $292904(165128,433$ 871) & $2.8 \mathrm{E}-4^{*}$ \\
\hline ornithine & 1385224 (1 083 311, 1721 772) & 1657626 (1 351 270, 1913 549) & $3.2 \mathrm{E}-4^{*}$ \\
\hline uracil & 6888567 (4 490 348, 9622 913) & 4784283 (3 740 917, 6592 407) & 5.7E-4 \\
\hline lactose & 3140699 (2 178 153, 4835 219) & 4519336 (2 900 447, 6650384$)$ & $3.8 \mathrm{E}-4$ \\
\hline xanthosine & $10839(7518,22311)$ & $22007(8845,36474)$ & $1.0 \mathrm{E}-3$ \\
\hline tyrosine & $222479(174354,277562)$ & $247875(210621,309004)$ & $2.2 \mathrm{E}-3$ \\
\hline serine & $352671(280146,415$ 607) & $381134(319491,476$ 035) & 4.6E-3 \\
\hline PEP & $312003(189719,522$ 172) & $462016(257705,925860)$ & $1.3 \mathrm{E}-3$ \\
\hline ribose-5-P-rib & $144443(104797,208$ 719) & $180078(116088,322$ 799) & 8.7E-3 \\
\hline
\end{tabular}

Values are median peak area for the metabolites (quartile 1, quartile 3 )

*P-value significant at the Bonferroni adjusted level of $3.0 \times 10-4$ 
Table 4 Cross sectional analysis of BMI tertiles and select metabolites

\begin{tabular}{|c|c|c|c|c|}
\hline & 1 & 2 & 3 & $P$ \\
\hline 20:4 carnitine & $296(246,378)$ & $263(216,324)$ & $253(207,292)$ & $7.8 \mathrm{E}-3$ \\
\hline b-OH-butyrate & $508950(249$ 015, 1818 943) & $395440(234716,895$ 354) & $343616(172233,717$ 989) & $2.9 \mathrm{E}-2$ \\
\hline benzoate & $15216(11526,24$ 891) & $18382(12$ 187, 28 788) & $21271(14892,34$ 600) & $4.1 \mathrm{E}-2$ \\
\hline 9:0 carnitine & $17878(11801,23836)$ & $16514(9560,24702)$ & $13239(9$ 472, 20 371) & $5.7 \mathrm{E}-2$ \\
\hline BAIBA & $49654(26452,107799)$ & $36205(24704,57849)$ & $38844(23864,74057)$ & $1.3 \mathrm{E}-1$ \\
\hline SDMA & $942527(769351,1098799)$ & $852551(750082,970184)$ & $826704(729114,1062038)$ & $7.4 \mathrm{E}-2$ \\
\hline niacinamide & $209151(170065,248736)$ & $214718(175857,281191)$ & $246744(187545,297341)$ & $6.8 \mathrm{E}-2$ \\
\hline p-creatine & $42402(31941,51249)$ & $47705(39559,61036)$ & $48786(37472,57166)$ & $4.0 \mathrm{E}-2$ \\
\hline succinate & 17776284 (15961 017, 22206915$)$ & 15637602 (12 262 309, 19434811$)$ & 16309449 (12 852 577, 19680091$)$ & $6.1 \mathrm{E}-3$ \\
\hline putrescine & $68559(44891,109979)$ & $54285(18371,87225)$ & $53504(12105,93032)$ & $1.3 \mathrm{E}-1$ \\
\hline XMP & $21819(11029,53$ 381) & $20694(8856,143900)$ & $37771(12$ 370, 121 441) & $1.7 \mathrm{E}-1$ \\
\hline adenine & $90351(61426,165$ 720) & 109819 (79 107, 201 534) & $116489(76$ 249, 194 627) & $1.1 \mathrm{E}-1$ \\
\hline glutamate & 870295 (691 881, 1109 208) & 992968 (715 437, 1375 593) & 1031076 (714 204, 1443 438) & $1.2 \mathrm{E}-1$ \\
\hline 3-PG & 2824102 (1 855508,4336 931) & 2788537 (1 930889,5190633$)$ & 3294065 (2 358 954, 5383 792) & $9.2 \mathrm{E}-2$ \\
\hline xanthosine & $12923(7425,24$ 088) & $10883(7$ 604, 33 249) & $19991(8413,30$ 597) & $1.7 \mathrm{E}-1$ \\
\hline
\end{tabular}

Values are median peak area for the metabolites (quartile 1, quartile 3)

*P-value significant at the Bonferroni adjusted level of $3.0 \times 10-4$

increased 1-year cardiovascular mortality among incident dialysis patients in ArMORR [27]. These observations raise the possibility that impaired mitochondrial respiration in muscle is linked to the pathogenesis of hypoalbuminemia in dialysis.

For individuals across tertiles of total cholesterol and SBP, PLS-DA again demonstrated moderate separation across tertiles (Figs. 4 and 5). For both analyses, longchain acylcarnitines were among the metabolites with the highest VIP scores, with 18:2 carnitine (linoleylcarnitine,
$P=9.0 \times 10^{-7}$ ), $18: 1$ carnitine (oleoylcarnitine, $P=6.0 \times$ $10^{-7}$ ), and 18:0 carnitine (stearoylcarnitine, $P=7.7 \times 10$ ${ }^{-5}$ ) all significantly higher in individuals with lower total cholesterol levels (Table 6,) and linoleylcarnitine $(P=$ $\left.5.5 \times 10^{-5}\right)$ and oleoylcarnitine $\left(P=8.7 \times 10^{-6}\right)$ significantly higher in individuals with lower SBP (Table 7); select short-chain and medium-chain acylcarnitines were also significantly elevated among individuals with lower SBP. Like albumin, low cholesterol and blood pressure are established predictors of increased mortality in ESRD

Table 5 Cross sectional analysis of albumin tertiles and select metabolites

\begin{tabular}{|c|c|c|c|c|}
\hline & 1 & 2 & 3 & $P$ \\
\hline kynurenine & $425998(298054,535$ 460) & $478927(395468,596735)$ & $552251(433248,679481)$ & $1.8 \mathrm{E}-4^{*}$ \\
\hline tryptophan & $273066(223467,413$ 194) & $315338(255914,423$ 927) & $393551(301885,501066)$ & $2.5 \mathrm{E}-4^{*}$ \\
\hline creatine & $2157292(1397576,3355$ 087) & $1907461(1145455,2791$ 140) & $1570693(1182$ 023, 2037 120) & $4.9 \mathrm{E}-3$ \\
\hline indoxylsulfate & $42510713(24175943,58375$ 318) & 55564881 (34 527474,67400 369) & 57398073 (33 359446,80148 935) & $1.3 \mathrm{E}-2$ \\
\hline 12:0 carnitine & $28261(18195,40622)$ & 30496 (18 540, 44 940) & $36915(24245,50553)$ & 2.7E-2 \\
\hline aspartate & $36448(25083,49840)$ & $34626(24685,48$ 518) & $26533(20$ 120, 36 067) & $1.9 \mathrm{E}-3$ \\
\hline thyroxine & $2332(1929,2$ 738) & $2523(1879,2916)$ & $2712(2115,3$ 244) & $1.8 \mathrm{E}-2$ \\
\hline indolelactate & $12722(8573,19334)$ & $15627(11$ 171, 22 311) & $16269(11922,22700)$ & 3.6E-2 \\
\hline BAIBA & $46979(27423,106593)$ & $42313(24$ 146, 80 713) & $34051(23583,57272)$ & 1.0E-1 \\
\hline alanine & $1280822(985$ 715, 1604 978) & $1249845(1028428,1494869)$ & $1337859(1117636,1758661)$ & $6.9 \mathrm{E}-2$ \\
\hline 10:0 carnitine & $33566(21210,61857)$ & $48413(25775,68$ 324) & $47884(31469,72628)$ & $5.8 \mathrm{E}-2$ \\
\hline SDMA & 896522 (765 176, 1090 288) & $925219(772578,1063$ 241) & $824248(730601,974$ 498) & $5.2 \mathrm{E}-2$ \\
\hline hydroxyproline & $235578(162$ 155, 374 510) & 203966 (149 720, 306 721) & $198496(150564,259$ 207) & $1.5 \mathrm{E}-1$ \\
\hline GCDCAs & 487186 (203 751, 773 938) & $421065(248114,748$ 019) & 715307 (356 712, 1064 255) & $1.4 \mathrm{E}-2$ \\
\hline ADP & $280998(155075,610$ 214) & $539330(278012,877605)$ & $455070(164681,1239020)$ & $1.2 \mathrm{E}-2$ \\
\hline
\end{tabular}

Values are median peak area for the metabolites (quartile 1, quartile 3)

*P-value significant at the Bonferroni adjusted level of $3.0 \times 10-4$ 
Table 6 Cross sectional analysis of total cholesterol tertiles and select metabolites

\begin{tabular}{|c|c|c|c|c|}
\hline & 1 & 2 & 3 & $P$ \\
\hline tryptophan & $440068(345$ 130, 586637) & $323192(257580,429806)$ & $274624(223120,324798)$ & $1.7 \mathrm{E}-9^{*}$ \\
\hline 18:2 carnitine & 60494 (38 250, 107 981) & $49737(27163,73$ 344) & $32084(19167,53$ 863) & $9.0 \mathrm{E}-7^{*}$ \\
\hline 18:1 carnitine & 88418 (58 090, 144 102) & $69442(40568,103$ 682) & $47134(33127,74763)$ & $6.0 \mathrm{E}-7^{*}$ \\
\hline 18:0 carnitine & $12789(10118,18$ 240) & $10879(7872,14622)$ & $8466(6$ 103, 12433$)$ & $7.7 \mathrm{E}-5^{*}$ \\
\hline arginine & $175576(136$ 362, 259 524) & $187566(132389,324$ 585) & $321420(216851,491848)$ & $9.6 \mathrm{E}-6^{*}$ \\
\hline 10:0 carnitine & $52498(28731,92$ 694) & $40556(26$ 190, 67 085) & $34244(20094,52420)$ & $7.0 \mathrm{E}-3$ \\
\hline glycocholate & $193580(60425,672001)$ & $105938(61765,208$ 013) & 76985 (42 135, 222 324) & $5.6 \mathrm{E}-3$ \\
\hline taurocholate & $128124(30180,379$ 765) & $91894(35067,188$ 948) & $47535(24706,128$ 025) & $1.9 \mathrm{E}-2$ \\
\hline GMP & $640409(341616,884$ 723) & $544860(409$ 493, 969 998) & 831864 (565 936, 1246 583) & $8.9 \mathrm{E}-3$ \\
\hline AMP & 2898935 (2 275762,3795 325) & 3153490 (2 679559,4251 281) & 3708724 (3 046 005, 4670016$)$ & $1.6 \mathrm{E}-3$ \\
\hline carnosine & $23811(15639,77$ 524) & $34287(14$ 160, 119 781) & $64617(29846,195$ 284) & $6.5 \mathrm{E}-3$ \\
\hline aminoadipate & $139402(119264,184$ 086) & $167760(130029,210$ 530) & $186821(144$ 705, 242 940) & $3.3 \mathrm{E}-3$ \\
\hline 16:1 carnitine & $68049(46259,99$ 787) & $65354(35653,77665)$ & $49527(39008,71026)$ & $2.1 \mathrm{E}-2$ \\
\hline 14:0 carnitine & 9893 (6 819, 17 108) & $8969(5$ 659, 12 834) & $7848(5373,10960)$ & $3.1 \mathrm{E}-2$ \\
\hline p-creatine & $42102(30390,51406)$ & $46713(36982,55$ 510) & $50600(37472,70045)$ & $1.8 \mathrm{E}-2$ \\
\hline
\end{tabular}

Values are median peak area for the metabolites (quartile 1, quartile 3 )

*P-value significant at the Bonferroni adjusted level of $3.0 \times 10-4$

$[8,9,11,12]$. These findings are consistent with our observation that long-chain acylcarnitines are associated with 1-year cardiovascular mortality in ESRD [27], and motivate further interest in long-chain acylcarnitines as markers, or even mediators, of altered lipid metabolism and cardiovascular function in uremia. Tryptophan, one of the strongest discriminators of albumin tertile, was also a top hit in regards to total cholesterol and SBP, with higher tryptophan significantly associated with lower levels for both. Finally, higher arginine levels were significantly associated with higher total cholesterol and higher deoxyadenosine levels were significantly associated with lower SBP.Values are median peak area for the metabolites (quartile 1, quartile 3)*P-value significant at the Bonferroni adjusted level of $3.0 \times 10-4$

\section{Relation of uremic solutes with twenty-four clinical phenotypes}

To examine the specificity of the long-chain acylcarnitinephenotype associations described above, we looked more

Table 7 Cross sectional analysis of systolic blood pressure tertiles and select metabolites

\begin{tabular}{|c|c|c|c|c|}
\hline & 1 & 2 & 3 & $P$ \\
\hline 14:0 carnitine & $10549(7384,17510)$ & $7855(6040,11626)$ & $6824(4844,9$ 486) & $9.0 \mathrm{E}-6^{*}$ \\
\hline tryptophan & $433424(297696,573$ 865) & $366630(261744,444$ 478) & $285101(229380,350$ 075) & $1.2 \mathrm{E}-6^{*}$ \\
\hline 18:1 carnitine & 86406 (56 919, 127 989) & $70273(47$ 764, 105 108) & $52275(32871,76$ 097) & 8.7E-6* \\
\hline 18:2 carnitine & $55715(35$ 972, 84 528) & $44392(31334,69$ 607) & $30733(21812,54$ 084) & $5.5 \mathrm{E}-5^{*}$ \\
\hline 3:0 carnitine & $770205(556$ 166, 976 463) & $604794(378$ 770, 724 282) & $549619(381463,708$ 095) & $5.4 \mathrm{E}-5^{*}$ \\
\hline deoxyadenosine & $882(605,1330)$ & $831(455,1011)$ & $571(441,787)$ & $7.5 \mathrm{E}-5^{*}$ \\
\hline 16:1 carnitine & $70042(50052,97483)$ & 53904 (39 997, 77 945) & $47577(36$ 257, 68 016) & $4.2 \mathrm{E}-4$ \\
\hline 18:0 carnitine & $12434(8777,17403)$ & $10456(7790,15$ 356) & 8806 (6 509, 12 276) & $4.2 \mathrm{E}-4$ \\
\hline carnitine & 4940542 (4 375772,5974 275) & 4311636 (3 616 956, 4936 736) & 4279513 (3 743 960, 4756 471) & $2.1 \mathrm{E}-5^{*}$ \\
\hline 12:0 carnitine & $39844(22621,61584)$ & $33433(22$ 258, 39 850) & $27094(17488,43033)$ & $8.5 \mathrm{E}-3$ \\
\hline kynurenic acid & $63185(35805,129$ 532) & $86131(60982,133796)$ & $116334(67598,169$ 586) & $9.4 \mathrm{E}-4$ \\
\hline tyrosine & $255780(216337,319$ 582) & $231195(200964,273$ 325) & 223332 (177 881, 270 817) & $8.4 \mathrm{E}-3$ \\
\hline ADMA & $309751(281$ 198, 370 574) & $290947(261$ 258, 344 552) & $284594(248$ 154, 328 619) & $1.1 \mathrm{E}-2$ \\
\hline taurocholate & 103888 (39 457, 284 746) & $65463(26$ 657, 196 110) & 59392 (25 323, 157 090) & $1.8 \mathrm{E}-2$ \\
\hline cytidine & $60033(36$ 540, 80 779) & $51105(32838,73$ 636) & $44821(26784,61200)$ & $2.1 \mathrm{E}-2$ \\
\hline
\end{tabular}




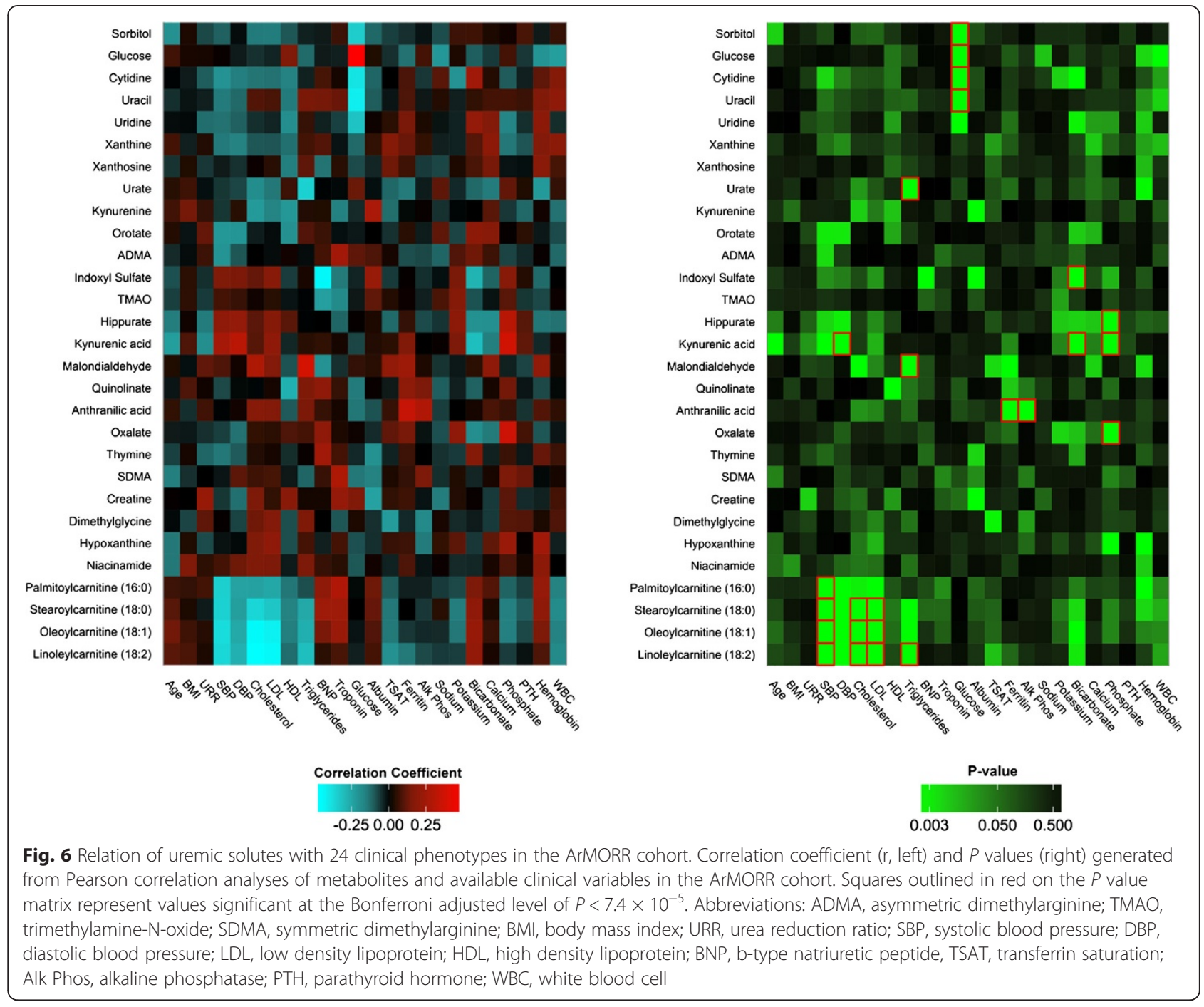

broadly at the correlation between all of the metabolites captured on our platform that are uremic retention solutes and 24 phenotypes captured in ArMORR. Correlations between previously reported uremic retention solutes measured by our LC-MS platform, including longchain acylcarnitines, and a broad array of clinical phenotypes measured in ArMORR are shown in Fig. 6 (full results are shown in Additional file 1: Tables S2 and S3). The correlations for glucose, as measured by the mass spectrometer, provide an anchor for interpreting this data - LC-MS glucose had a strong positive correlation with glucose measured by the clinical laboratory $(r=0.80$, $\left.P<10^{-15}\right)$, and a modest negative correlation with serum sodium $\left(r=-0.21, P=7.0 \times 10^{-3}\right)$ that did not reach statistical significance, but is well recognized in the clinic (i.e. dilutional hyponatremia due to hyperglycemia). Aside from the correlation between the two glucose measures, the strongest correlations identified by this broader examination of uremic metabolites were indeed between long- chain acylcarnitines and lipid traits (total and LDL cholesterol) and blood pressure. Among lipid phenotypes, long-chain acylcarnitines such as oleoylcarnitine were more strongly correlated with total $\left(r=-0.45, P=2.6 \times 10^{-9}\right)$ and LDL cholesterol $\left(r=-0.43 ., P=1.7 \times 10^{-8}\right)$ than with HDL cholesterol $\left(r=-0.15, P=5.7 \times 10^{-2}\right)$ or triglycerides $(r=$ $\left.-0.27, P=5.0 \times 10^{-4}\right)$. Similarly, oleoylcarnitine was more strongly correlated with SBP $\left(r=-0.38, P=3.4 \times 10^{-8}\right)$ than diastolic blood pressure $\left(r=-0.25, P=3.0 \times 10^{-3}\right)$. Longchain acylcarnitines were not significantly correlated with any non-lipid or non-blood pressure phenotype.

Among the other uremic retention solutes included in our analysis, only kynurenic and anthranilic acid (both tryptophan metabolites downstream of IDO) had more than one significant correlation with a clinical variable (Fig. 6). Kynurenic acid was significantly correlated with diastolic blood pressure $\left(r=0.32, P=5.0 \times 10^{-6}\right)$, bicarbonate $(r=$ $\left.-0.31, P=1.1 \times 10^{-5}\right)$, and phosphorous $(r=0.38, \quad P=5.7 \times$ $10^{-8}$ ), whereas anthranilic acid was significantly correlated 
with alkaline phosphatase $\left(\mathrm{r}=0.29, P=6.3 \times 10^{-5}\right)$ and ferritin $\left(r=0.35, P=9.7 \times 10^{-7}\right)$, a frequently used marker of inflammation in hemodialysis. Notably, the other metabolites that had a nominal association with ferritin included two other tryptophan metabolites, kynurenic acid $(r=0.16, P=$ $\left.2.6 \times 10^{-2}\right)$ and quinolinate $\left(r=0.20, P=6.3 \times 10^{-3}\right)$, and malondialydehyde $\left(r=0.24, \quad P=9.0 \times 10^{-4}\right)$, an oxidative stress marker. These findings reinforce a potential link between the IDO pathway and uremic inflammation. Sorbitol $\left(r=-0.34, P=3.4 \times 10^{-5}\right)$, cytidine $(\mathrm{r}=-0.40, P=1.1 \times 10$ $\left.{ }^{-6}\right)$, and uracil $\left(\mathrm{r}=-0.42, \quad P=1.7 \times 10^{-7}\right)$ were significantly correlated with plasma glucose; urate $(r=-0.35, P=5.2 \times 10$ $\left.{ }^{-6}\right)$ and malondialdehyde $\left(r=0.38, P=5.7 \times 10^{-7}\right)$ were significantly correlated with triglycerides; hippurate $(r=0.31, P$ $\left.=7.0 \times 10^{-6}\right)$ and oxalate $\left(r=0.36, P=1.6 \times 10^{-7}\right)$ were significantly correlated with phosphorous; and indoxyl sulfate $\left(r=-0.28, \quad P=6.8 \times 10^{-5}\right)$ was significantly correlated with bicarbonate. Indoxyl sulfate, which has been found to have several proinflammatory effects in model systems [52], had no correlation with ferritin (nor transferrin saturation, nor white blood cell count), but had a trend for a negative correlation with BNP $\left(r=-0.44, P=4.0 \times 10^{-4}\right)$.

Although significant work has been devoted to understanding the in vitro effects of uremic retention solutes, less is known about how many of these metabolites relate to clinical traits in humans. Thus, in addition to demonstrating the specificity of select long-chain acylcarnitine associations, our examination of uremic metabolites against clinical phenotypes provides a resource for future uremic toxin research.

\section{Limitations}

Our study has several limitations. First, by examining crosssectional relationships between metabolite levels and various clinical phenotypes, our study is unable to address causation. Instead, by applying parsimonious selection procedures and conservative adjusted significance thresholds, we seek to highlight notable associations for future investigations. Second, study subjects were selected in the context of a casecontrol study of 1-year cardiovascular mortality, raising the possibility of confounding by case status. However, as noted in the Methods, the statistical significance of the findings are not changed when analyzed stratified by case status. Nevertheless, we acknowledge that our sample is not a random selection of incident dialysis patients, potentially limiting the generalizability of our findings. Third, residual confounding from other sources is likely to influence the associations described, as multivariate adjustments were not pursued. However, because the relationship between various clinical phenotypes and metabolite levels in uremia is unknown, we did not want to obscure novel biological associations by statistical adjustment. Thus, we present these raw associations as a framework for interpreting and appropriately adjusting select findings in future metabolomics studies in ESRD.
Finally, our results require replication in an independent sample, ideally selected randomly and including both incident and prevalent dialysis patients.

\section{Conclusions}

In this report, we describe the small molecule alterations that accompany various metabolic phenotypes in ESRD. For phenotypes like diabetes and obesity that have been examined using metabolomics in the general population, our data reinforce the notion that unique pathophysiologic processes arise at ESRD onset. Our finding that long-chain acylcarnitines are strongly and inversely correlated with cholesterol and blood pressure corroborate their potential value as markers of cardiovascular risk in ESRD, whereas the association of tryptophan levels across several phenotypes is of interest given recent studies that assign a functional role for tryptophan metabolism in inflammation and vascular biology. Ultimately, we hope that the breadth of the data presented herein serves as a springboard for investigating mechanisms of uremic toxicity and identifying therapeutic targets to improve the unacceptably high morbidity and mortality attributable to ESRD.

\section{Additional file}

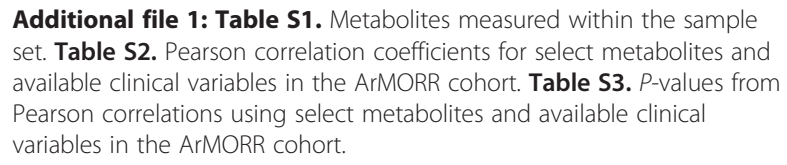

\section{Abbreviations}

ESRD: End stage renal disease; LDL: Low density lipoprotein; BMl: Body mass index; LC-MS: Liquid chromatography-mass spectrometry; ArMORR cohort: Accelerated Mortality on Renal Replacement cohort; SBP: Systolic blood pressure; PLS-DA: Partial least squares discriminant analysis; VIP: Variable importance in projection; XMP: Xanthosine-5-phosphate; VMA: Vanillylmandelic acid; IDO: Indoleamine-2,3-dioxygenase; BNP: b-type natriuretic peptide.

\section{Competing interests}

The authors declare that they have no competing interests.

\section{Authors' contributions}

SK and EPR designed the study, performed the statistical analysis, and wrote the manuscript. EPR and CBC performed the MS experiments. JJD, GO, ASM helped with sample processing, data analysis, and generating figures. REG aided with study design, data analysis, and manuscript drafting. RT established the cohort from which plasma samples were derived. All authors read and approved the final manuscript.

\section{Acknowledgements}

SK received support from the National Kidney Foundation Young Investigator award and NIH award KL2TR001100; EPR was supported by the Extramural Grant Program by Satellite Healthcare, a not-for-profit renal care provider, and NIH grant K08-DK-090142. REG received support from NIH 2R01DK081572 and NIH 1R01 HL098280; RT received support from NIH award K24 DK094872.

\section{Author details}

${ }^{1}$ Division of Nephrology, Massachusetts General Hospital (MGH), 165 Cambridge Street, Suite 302, Boston, MA 02114, USA. ${ }^{2}$ Broad Institute, 
Cambridge, MA, USA. ${ }^{3}$ Cardiology Division, MGH, Boston, MA, USA.

${ }^{4}$ Cardiovascular Research Center, MGH, Boston, MA, USA.

Received: 25 March 2015 Accepted: 28 June 2015 Published online: 07 July 2015

\section{References}

1. Kopple JD. How to reconcile conventional and altered risk factor patterns in dialysis patients. Semin Dial. 2007;20(6):602-5.

2. Kalantar-Zadeh K, Kilpatrick RD, Kuwae N, McAllister CJ, Alcorn Jr H, Kopple $J \mathrm{D}$, et al. Revisiting mortality predictability of serum albumin in the dialysis population: time dependency, longitudinal changes and populationattributable fraction. Nephrol Dial Transplant. 2005:20(9):1880-8.

3. Kovesdy CP, Kalantar-Zadeh K. Why is protein-energy wasting associated with mortality in chronic kidney disease? Semin Nephrol. 2009;29(1):3-14.

4. Cano NJ, Fouque D, Roth H, Aparicio M, Azar R, Canaud B, et al. Intradialytic parenteral nutrition does not improve survival in malnourished hemodialysis patients: a 2-year multicenter, prospective, randomized study. J Am Soc Nephrol. 2007;18(9):2583-91.

5. Dukkipati R, Kopple JD. Causes and prevention of protein-energy wasting in chronic kidney failure. Semin Nephrol. 2009;29(1):39-49.

6. Fellstrom BC, Jardine AG, Schmieder RE, Holdaas H, Bannister $K$, Beutler J, et al. Rosuvastatin and cardiovascular events in patients undergoing hemodialysis. N Engl J Med. 2009:360(14):1395-407.

7. Wanner C, Krane V, Marz W, Olschewski M, Mann JF, Ruf G, et al. Atorvastatin in patients with type 2 diabetes mellitus undergoing hemodialysis. N Engl J Med. 2005;353(3):238-48.

8. Kalantar-Zadeh K, Block G, Humphreys MH, Kopple JD. Reverse epidemiology of cardiovascular risk factors in maintenance dialysis patients. Kidney Int. 2003;63(3):793-808.

9. Lowrie EG, Lew NL. Death risk in hemodialysis patients: the predictive value of commonly measured variables and an evaluation of death rate differences between facilities. Am J Kidney Dis. 1990;15(5):458-82.

10. Kopple JD, Zhu X, Lew NL, Lowrie EG. Body weight-for-height relationships predict mortality in maintenance hemodialysis patients. Kidney Int 1999;56(3):1136-48

11. Iseki K, Miyasato F, Tokuyama K, Nishime K, Uehara H, Shiohira Y, et al. Low diastolic blood pressure, hypoalbuminemia, and risk of death in a cohort of chronic hemodialysis patients. Kidney Int. 1997;51(4):1212-7.

12. Port FK, Hulbert-Shearon TE, Wolfe RA, Bloembergen WE, Golper TA, Agodoa $L Y$, et al. Predialysis blood pressure and mortality risk in a national sample of maintenance hemodialysis patients. Am J Kidney Dis. 1999;33(3):507-17.

13. Newgard CB, An J, Bain JR, Muehlbauer MJ, Stevens RD, Lien LF, et al. A branched-chain amino acid-related metabolic signature that differentiates obese and lean humans and contributes to insulin resistance. Cell Metab. 2009:9(4):311-26.

14. Wang TJ, Larson MG, Vasan RS, Cheng S, Rhee EP, McCabe E, et al. Metabolite profiles and the risk of developing diabetes. Nat Med. 2011:17(4):448-53.

15. Menni C, Fauman E, Erte I, Perry JR, Kastenmuller G, Shin SY, et al. Biomarkers for type 2 diabetes and impaired fasting glucose using a nontargeted metabolomics approach. Diabetes. 2013;62(12):4270-6.

16. Floegel A, Stefan N, Yu Z, Muhlenbruch K, Drogan D, Joost HG, et al. Identification of serum metabolites associated with risk of type 2 diabetes using a targeted metabolomic approach. Diabetes. 2013;62(2):639-48.

17. Cheng S, Rhee EP, Larson MG, Lewis GD, McCabe EL, Shen D, et al. Metabolite profiling identifies pathways associated with metabolic risk in humans. Circulation. 2012;125(18):2222-31.

18. Wewalka M, Patti ME, Barbato C, Houten SM, Goldfine AB. Fasting Serum Taurine-conjugated Bile Acids are Elevated in Type 2 Diabetes: and Do Not Change with Intensification of Insulin. J Clin Endocrinol Metab. 2014:99(4):1442-51. doi:10.1210/jc.2013-3367. Epub 2014 Jan 16.

19. Gerhard GS, Styer AM, Wood GC, Roesch SL, Petrick AT, Gabrielsen J, et al. A role for fibroblast growth factor 19 and bile acids in diabetes remission after Roux-en-Y gastric bypass. Diabetes Care. 2013;36(7):1859-64.

20. Ridaura VK, Faith JJ, Rey FE, Cheng J, Duncan AE, Kau AL, et al. Gut microbiota from twins discordant for obesity modulate metabolism in mice. Science. 2013;341(6150):1241214.

21. Wang-Sattler R, Yu Z, Herder C, Messias AC, Floegel A, He Y, et al. Novel biomarkers for pre-diabetes identified by metabolomics. Mol Syst Biol. 2012;8:615.

22. McCormack SE, Shaham O, McCarthy MA, Deik AA, Wang TJ, Gerszten RE, et al. Circulating branched-chain amino acid concentrations are associated with obesity and future insulin resistance in children and adolescents. Pediatr Obes. 2013:8(1):52-61.

23. Moore SC, Matthews CE, Sampson JN, Stolzenberg-Solomon RZ, Zheng W, Cai Q, et al. Human metabolic correlates of body mass index. Metabolomics. 2014;10(2):259-69.

24. Atzler D, Schwedhelm E, Zeller T. Integrated genomics and metabolomics in nephrology. Nephrol Dial Transplant. 2014;29(8):1467-74.

25. Rhee EP, Souza A, Farrell L, Pollak MR, Lewis GD, Steele DJ, et al. Metabolite profiling identifies markers of uremia. J Am Soc Nephrol. 2010;21 (6):1041-51.

26. Sato E, Kohno M, Yamamoto M, Fujisawa T, Fujiwara K, Tanaka N. Metabolomic analysis of human plasma from haemodialysis patients. Eur J Clin Invest. 2011;41(3):241-55.

27. Kalim S, Clish CB, Wenger J, Elmariah S, Yeh RW, Deferio JJ, et al. A plasma long-chain acylcarnitine predicts cardiovascular mortality in incident dialysis patients. J Am Heart Assoc. 2013;2(6), e000542.

28. Gutierrez OM, Mannstadt M, Isakova T, Rauh-Hain JA, Tamez H, Shah A, et al. Fibroblast growth factor 23 and mortality among patients undergoing hemodialysis. N Engl J Med. 2008;359(6):584-92.

29. Teng M, Wolf M, Lowrie E, Ofsthun N, Lazarus JM, Thadhani R. Survival of patients undergoing hemodialysis with paricalcitol or calcitriol therapy. N Engl J Med. 2003;349(5):446-56.

30. Teng M, Wolf M, Ofsthun MN, Lazarus JM, Hernan MA, Camargo Jr CA, et al. Activated injectable vitamin D and hemodialysis survival: a historical cohort study. J Am Soc Nephrol. 2005;16(4):1115-25.

31. Thadhani R, Tonelli M. Cohort studies: marching forward. Clin J Am Soc Nephrol. 2006:1(5):1117-23.

32. Rhee EP, Clish CB, Ghorbani A, Larson MG, Elmariah S, McCabe E, et al. Wang TJ. Gerszten RE. A combined epidemiologic and physiologic metabolomics approach improves chronic kidney disease prediction. J AM Soc Nephrol: Fox CS; 2013.

33. Kilpatrick RD, McAllister CJ, Kovesdy CP, Derose SF, Kopple JD, Kalantar-Zadeh K. Association between serum lipids and survival in hemodialysis patients and impact of race. J Am Soc Nephrol. 2007;18(1):293-303.

34. Kalantar-Zadeh K, Kilpatrick RD, McAllister CJ, Greenland S, Kopple JD. Reverse epidemiology of hypertension and cardiovascular death in the hemodialysis population: the 58th annual fall conference and scientific sessions. Hypertension. 2005;45(4):811-7.

35. Kalantar-Zadeh K, Kopple JD, Kilpatrick RD, McAllister CJ, Shinaberger CS, Gjertson DW, et al. Association of morbid obesity and weight change over time with cardiovascular survival in hemodialysis population. Am J Kidney Dis. 2005:46(3):489-500.

36. Bradbury BD, Fissell RB, Albert JM, Anthony MS, Critchlow CW, Pisoni RL, et al. Predictors of early mortality among incident US hemodialysis patients in the Dialysis Outcomes and Practice Patterns Study (DOPPS). Clin J Am Soc Nephrol. 2007;2(1):89-99.

37. Trivedi $H$, Xiang Q, Klein JP. Risk factors for non-fatal myocardial infarction and cardiac death in incident dialysis patients. Nephrol Dial Transplant. 2009;24(1):258-66

38. Kovesdy CP, Kalantar-Zadeh K. Introduction: the reverse epidemiology controversy. Semin Dial. 2007;20(6):485.

39. Rhee CM, Leung AM, Kovesdy CP, Lynch KE, Brent GA, Kalantar-Zadeh K. Updates on the management of diabetes in dialysis patients. Semin Dial. 2014:27(2):135-45

40. Xia J, Mandal R, Sinelnikov IV, Broadhurst D, Wishart DS. MetaboAnalyst 2.0-a comprehensive server for metabolomic data analysis. Nucleic Acids Res. 2012;40(Web Server issue):W127-33. doi:10.1093/nar/gks374 Epub 2012 May 2

41. Xia J, Psychogios N, Young N, Wishart DS. MetaboAnalyst: a web server for metabolomic data analysis and interpretation. Nucleic Acids Res. 2009;37(Web Server issue):W652-60.

42. Vanholder R, Abou-Deif O, Argiles A, Baurmeister U, Beige J, Brouckaert P, et al. The role of EUTox in uremic toxin research. Semin Dial. 2009:22(4):323-8.

43. Vanholder R, Baurmeister U, Brunet P, Cohen G, Glorieux G, Jankowski J. A bench to bedside view of uremic toxins. J Am Soc Nephrol. 2008;19(5):863-70

44. Vanholder R, De Smet R, Glorieux G, Argiles A, Baurmeister U, Brunet P, et al. Review on uremic toxins: classification, concentration, and interindividual variability. Kidney Int. 2003:63(5):1934-43.

45. Duranton F, Cohen G, De Smet R, Rodriguez M, Jankowski J, Vanholder R, et al. Normal and pathologic concentrations of uremic toxins. J Am Soc Nephrol. 2012;23(7):1258-70. 
46. Tessari P, Deferrari G, Robaudo C, Vettore M, Pastorino N, De Biasi L, et al. Phenylalanine hydroxylation across the kidney in humans rapid communication. Kidney Int. 1999;56(6):2168-72.

47. Reaich D, Channon SM, Scrimgeour CM, Daley SE, Wilkinson R, Goodship $\mathrm{TH}$. Correction of acidosis in humans with CRF decreases protein degradation and amino acid oxidation. Am J Physiol. 1993;265(2 Pt 1):E230-5.

48. Wang Y, Liu H, McKenzie G, Witting PK, Stasch JP, Hahn M, et al. Kynurenine is an endothelium-derived relaxing factor produced during inflammation. Nat Med. 2010;16(3):279-85.

49. Munn DH, Mellor AL. Indoleamine 2,3 dioxygenase and metabolic control of immune responses. Trends Immunol. 2013;34(3):137-43.

50. Jourde-Chiche N, Dou L, Cerini C, Dignat-George F, Vanholder R, Brunet P. Protein-bound toxins-update 2009. Semin Dial. 2009;22(4):334-9.

51. Shaham O, Slate NG, Goldberger O, Xu Q, Ramanathan A, Souza AL, et al. A plasma signature of human mitochondrial disease revealed through metabolic profiling of spent media from cultured muscle cells. Proc Natl Acad Sci U S A. 2010;107(4):1571-5.

52. Pletinck A, Glorieux G, Schepers E, Cohen G, Gondouin B, Van Landschoot $M$, et al. Protein-bound uremic toxins stimulate crosstalk between leukocytes and vessel wall. J Am Soc Nephrol. 2013;24(12):1981-94.

\section{Submit your next manuscript to BioMed Central and take full advantage of:}

- Convenient online submission

- Thorough peer review

- No space constraints or color figure charges

- Immediate publication on acceptance

- Inclusion in PubMed, CAS, Scopus and Google Scholar

- Research which is freely available for redistribution 